\title{
PIGMENTED LESIONS OF THE CONJUNCTIVA. III
}

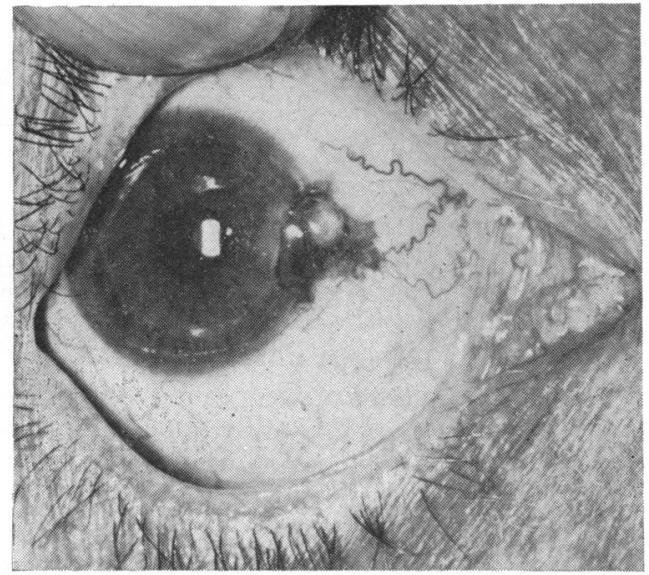

Fig. 11.-Compound naevus.

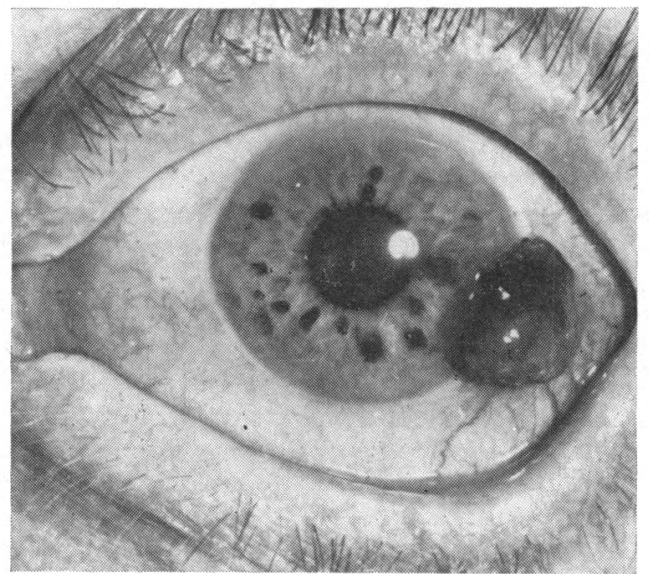

FIG. 12.-Localized malignant melanoma.

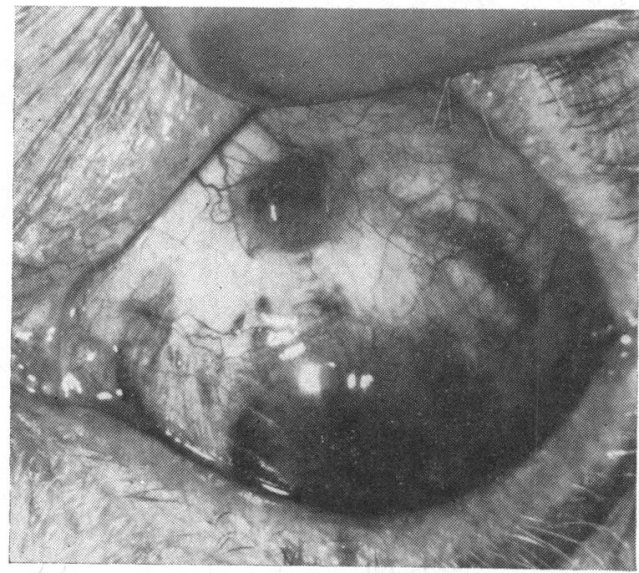

FIG. 13.-Widespread malignant melanoma.

\section{Raised Lesions}

Naevi Other than Junctional Naevi (Fig. 11)

Compound naevi, subepithelial naevi, and blue naevi of the conjunctiva all present as raised, usually pigmented lesions. In most instances they first appear in childhood or adolescence and seldom grow during adult life, although they may become more pigmented during pregnancy. On slit-lamp examination cysts are frequently seen within their substance. These tumours seldom grow to the size reached by many malignant melanomata.

Localized Malignant Melanoma (Fig. 12)

These usually appear in middle or old age and, if untreated, are progressive lesions. The majority appear to arise de novo or from a localized patch of flat pigmentation; occasionally a naevus of the conjunctiva may undergo malignant change. Increase in size in adult life should be regarded with suspicion; malignant melanomata in childhood or adolescence are extremely rare.

\section{Widespread Malignant Melanoma (Fig. 13)}

This is a raised lesion that appears in an area of widespread flat acquired pigmentation of the conjunctiva (widespread intra-epithelial melanoma or precancerous melanosis). The tumour may be single or multiple and may occur many years after the appearance of a widespread intra-epithelial melanoma. 


\section{Pathology}

\section{Naevi Other than Junctional Naevi}

In compound naevi, as in junctional naevi, there are circumscribed nests of naevus cells at the junctional zone; in addition there are nests of naevus cells within the subepithelial tissue (Fig. 14). In subepithelial naevi, which comprise about one quarter of all naevi of the conjunctiva, there is no junctional activity; only subepithelial nests of naevus cells are present. In the uncommon blue naevi, the tumour consists of characteristic spindleshaped cells situated deep in the subepithelial tissue.

\section{Localized Malignant Melanoma (Fig. 15)}

In this tumour epithelial-like or pleomorphic tumour cells, which have arisen from the malignant transformation of cells in the basal layer of the epithelium, have invaded the subepithelial tissue. Localized malignant melanomata which contain areas of apparently benign naevus cells, or epithelial downgrowths, have probably arisen from malignant change in a naevus.

\section{Widespread Malignant Melanoma (Fig. 16)}

This tumour may be indistinguishable histologically from a localized malignant melanoma unless it is surrounded by an extensive area of widespread intra-epithelial melanoma. A widespread malignant melanoma occurs when the subepithelial tissue is invaded by malignant tumour cells.

\section{Illustrations:}

INSTITUTE OF OPHTHALMOLOGY, JUDD STREeT, LONDON, W.C.1.

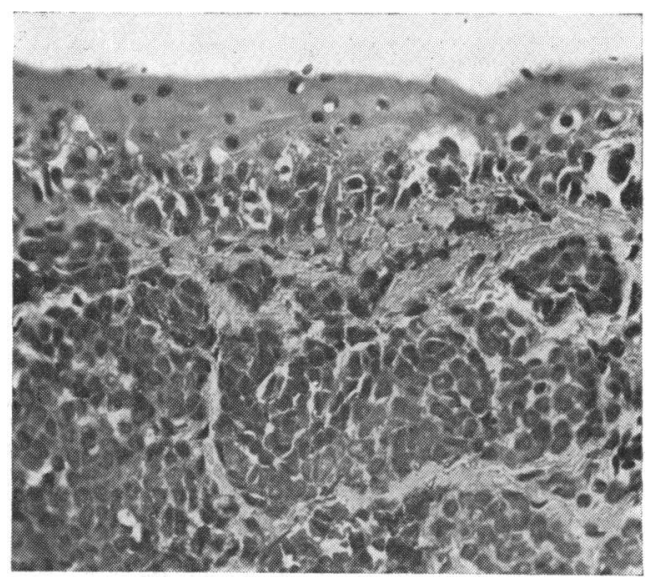

Fig. 14.-Compound naevus. Haematoxylin and eosin. $\times 167$

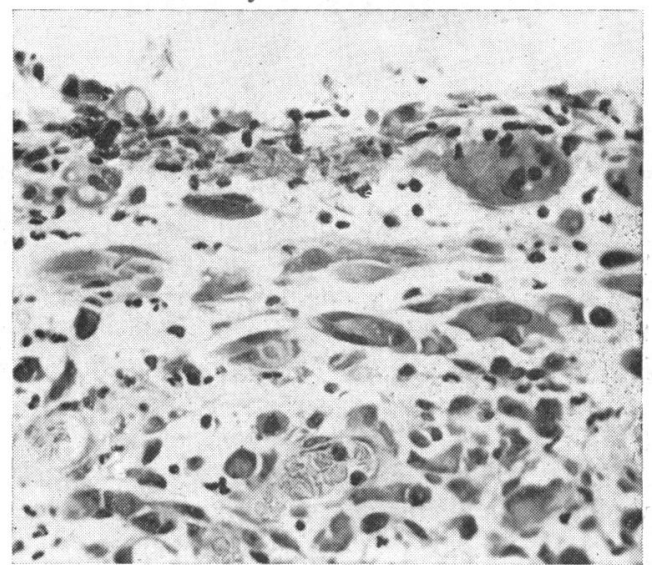

FIG. 15.--Localized malignant melanoma. Haematoxylin and eosin. $\times 167$.

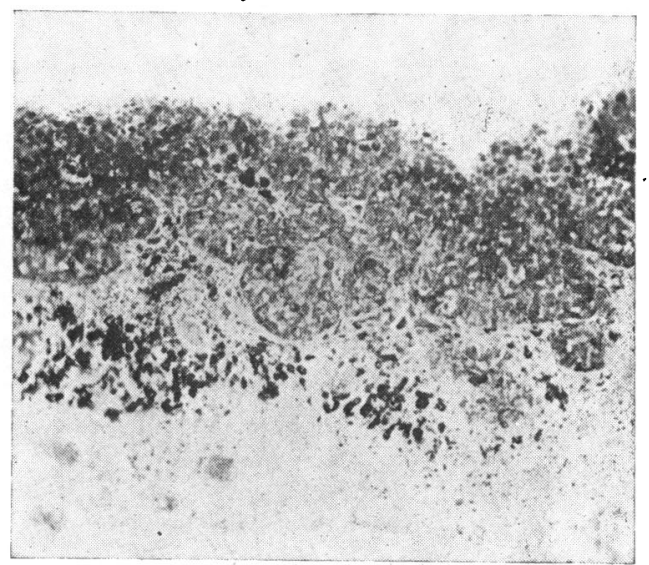

Fig. 16.-Widespread malignant melanoma. Haematoxylin and eosin. $\times 42$.

BARRIE JAY, THE LONDON HosPITAL, LONDON, E.1. 